\title{
EFEKTIVITAS SUPPORTIVE THERAPY TERHADAP KEMAMPUAN KELUARGA DALAM MERAWAT PASIEN DENGAN HEMODIALISA
}

\author{
${ }^{1}$ Windy Astuti Cahya Ningrum \\ Program Studi Diploma III Keperawatan IKesT Muhammadiyah Palembang \\ Email: indyak84@gmail.com
}

\begin{abstract}
ABSTRAK
Hemodialisa merupakan tindakan medis yang dilakukan pada pasien dengan gagal ginjal kronk dan berfungsi sebagai mesin pengganti ginjal yang digunakan oleh pasien. Klien harus menjalani hemodialisa sepanjang hidup atau sampai mendapatkan ginjal baru, hal ini dapat mempengaruhi kondisi fisik dan psikologis klien seperti ketidakberdayaan, keputusasaan sehingga dibutuhkan dukungan keluarga. Suportive therapy merupakan alternatif pilihan terapi yang ditujukan untuk meningkatkan kemampuan keluarga sebagai support system. Penelitian ini bertujuan untuk mengetahui efektivitas supportive therapy terhadap kemampuan keluarga dalam merawat pasien dengan gagal ginjal kronik. Metode Penelitian ini menggunakan desain quasy experiment pre post test control group dengan jumlah sampel 52 orang responden. Penelitian ini dilakukan di Rumah Sakit Pusri Palembang Juli 2017. Hasil penelitian didapatkan rata-rata responden berusia 42 tahun dengan lama rawat rata-rata 24 bulan. Sebagian besar responden berjenis kelamin perempuan, tidak bekerja dan berpendidikan SMU dengan rata-rata nilai kemampuan kognitif 46,6, kemampuan afektif 12,5 dan kemampuan psikomotor 24,3. Hasil analisis wilcoxon menunjukkan bahwa terdapat perbedaan antara kemampuan keluarga sebelum dan sesudah pemberian supportive therapy dengan rentang selisih 5,85-7,81 dengan $\mathrm{P}$ value $<0,05$. Dapat disimpulkan Supportive therapy berpengaruh terhadap peningkatan kemampuan keluarga dalam merawat klien gagal ginjal kronik. Disarankan peneliti selanjutnya untuk mengembangkan bentuk terapi lain yang terkait dalam upaya meningkatkan kemampuan keluarga merawat klien dengan gagal ginjal kronik.
\end{abstract}

Kata Kunci: Supportive Therapy, Kemampuan Keluarga, Hemodialisa

\begin{abstract}
Hemodialysis is a medical procedure on chronic kidney disease patients and serves as a kidney replacement machine used by the patients. Patients must undergo hemodialysis lifetime or until they receive a kidney transplant. This can affect their physical and psychological conditions such as helplessness and hopelessness so that family support is needed. Supportive therapy is an alternative therapy option at improving family abilities as a support system. This study was aimed to determine the effectiveness of supportive therapy on family abilities in caring for chronic kidney disease patients. This study was used a quasi experimental pre-posttest with control group design with a sample of 52 respondents. This study was conducted in Pusri Hospital Palembang on July 2017. Average age of respondents was 42 years old with average length of care for 26 weeks, Most of respondents were female, unemployed and has senior highschool education background with average cognitive ability score 46,6, affective ability 12,5 and psychomotor ability 24,3 . Wilcoxon analysis showed
\end{abstract}


that there was a difference between family ability before and after supportive therapy with a range of 5.85-7.81 difference with $\mathrm{P}$ value $<0.05$. Supporive therapy has an effect on improving family abilities in caring for chronic kidney disease patients . It is recommended for further researchers to develop other related forms of therapy to improve the family's ability to care clients with chronic kidney disease.

Key Words: Supportive Therapy, Family Ability, Hemodialysis

\section{PENDAHULUAN}

Insiden GGK masih menjadi masalah besar di dunia. Selain sulit disembuhkan, biaya perawatan dan pengobatannya pun sangat mahal (Chen et al., 2009; Russell et al., 2011). Secara global lebih dari 500 juta orang mengalami GGK. Diperkirakan jumlah pasien gagal ginjal kronik memiliki prevalensi yang semakin meningkat, tahun 2025 di Asia Tenggara, Mediaterania dan Timur Tengah serta Afrika diperkirakan mencapai lebih dari 380 juta orang. Peningkatan jumlah pasien gagal ginjal tersbut dapat dipengaruhi oleh beberapa faktor diantaranya pertumbuhan penduduk, peningkatan proses penuaan, urbanisasi, obesitas da gaya hidup tidak sehat.

Peningkatan jumlah pasien yang menderita gagal ginjal tersebut memerlukan berbagai penanganan antara lain dengan hemodialisis, dialisis peritonial atau hemofiltrasi, dan transpalantasi ginjal, dimana hal terpenting yang harus dilakukan oleh pasien dengan gagal ginjal yaitu dengan membatasi jumlah cairan dan obat untuk mencegah komplikasi serius serta lamanya penanganan tergantung pada penyebab dan luasnya kerusakan ginjal. Tindakan medis yang umum dilakukan pasien dengan gagal ginjal kronik adalah hemodialisa. Hemodialisa merupakan mesin pengganti ginjal yang digunakan oleh pasien gagal ginjal kronik.

Terapi hemodialisa bagi penderita GGK merupakan upaya untuk mencegah kematian atau memperpanjang usia (Smeltzer, 2008). Namun demikian, hemodialisa tidak dapat menyembuhkan atau memulihkan penyakit ginjal. Hemodialisa juga tidak mampu mengimbangi hilangnya aktivitas metabolik atau endokrin oleh ginjal dan dampak dari gagal ginjal serta terapi terhadap kualitas hidup klien. Klien harusmenjalani dialisis sepanjang hidupnya atau sampai mendapat ginjal baru melalui operasi pencangkokan dimana hal ini dapat mempengaruhii kondisi tubuh seseorang erhadap tindakan tersebut baik perubahan secara fisik maupun psikologis.

Penelitian yang dilakukan oleh Wahyuningsih (2011) tentang klien dengan gagal ginjak kronik didapatkan bahwa klien yang divonis menderita GGK dan harus menjalani hemodialisa ditemukan mengalami shock, tidak menerima dan stress pada awal-awal mereka di diagnosa menderita GGK. Klien merasakan bahwa menederita GGK adalah askhir segalanya dan mengganggapdirinya tidak beguna, membebani keluarga dan tidak dapat beraktivitas kembali. Penelitian lain juga dilakukan oleh Kristyaningsih (2009) yang menyatakan bahwa sebanyak $20 \%$ klien mengalami depresi dimana hal ini terjadi karena klien GGK merasakan kehilangan salah satu organ yang tidak dapat diganti dengan organ tubuh lainnya.

Dukungan keluarga merupakan salah satu faktor yang dapat mempengaruhi proses penyembuhan baik secara fisik 
maupun mental diantaranya memberikan motivasi pada pasien selama menjalani hemodialisa. Keterlibatan anggota keluarga dalam pemberian asuhan kesehatan merupakan suatu sistem dalam upaya membantu anggota keluarga yang sakit dalam mengontril diri dan juga dapat mempengaruhi komunitas pemberdayaan individu dan keluarga sebagai suatu sistem dalam komunitas, dimana hal ini memiliki tujuan meningkatkan pengetahuan, keterampilan dan kapasitas keluarga agar dapat menjjadi pelindung bagi keluarga sendiri (Keliat, 2003; Friedman, 2017 dan Hernawaty, 2010).

Keterlibatan keluarga dalam merawat anggota keluarga perlu didasari dengan pemahaman dan empati dengan fokus kekuatan pemberi perawatan dan motivasi selama perawatan pasien. Suatu tindakan diperlukan untuk meningkatkan kemampuan keluarga dalam merawat anggota keluarga yang sakit khususnya dalam hal ini adalah pasien dengan gagal ginjal kronik (GGK) yang akan berperan sebagai anggota keluarga sekaligus keluarga yang mampu memotivasi anggota keluarga yang sakit agar tetap semangat dalam menjalani terapi hemodialisa yang berlangsung cukup lama. Keterlibatan keluarga dalam merawat pasien yang menjalani hemodialisa dapat menimbulkan berbagai respon diantaranya kebosanan mengatar pasien ke tempat pelayanan kesehatan, kehilangan haraapan pada pasien untuk tetap dapat bertahan hidup bahkan ketergantungan pasien dengan anggota keluarga secara total sehingga keluarga sendiri selaku pemberi asuhan kesehatan membutuhkan dukungan yang salah satunya melalui terapi motivasi (Widiastuti, 2010).

Supportive therapy merupakan salah satu alternatif terapi yang dapat diberikan kepada keluarga untuk meningkatkan kemampuan keluarga dalam memberikan asuhan kesehatan, mengurangi beban keluarga dan meningkatkan koping keluarga serta meningkatkan dukungan sosial. Penelitian tentang supportive therapy yang dilakukan oleh Hernawaty (2009) dan Widiastuti (2010) menunjukan bahwa kemampuan kelompok keluarga yang mendapatkan terapi suportif keluarga meningkat lebih tinggi secara bermakna dibandingkan dengan kelompok keluarga yang tidak mendapatkan terapi suportif keluarga.

Berdasarkan uaraian diatas maka penulis tertarik untuk melakukan penelitian efektivitas supportive therapy terhadap kemampuan keluarga dalam merawat pasien dengan hemodialisa.

\section{METODE PENELITIAN}

Penelitian ini menggunakan desain penelitian quasy experiment pre post test control gruop dengan intervensi supportive therapy pada keluarga dengan subjek penelitian adalah anggota keluarga yang merawat pasien dengan terapi hemodialisa di di RS PUSRI Palembang tahun 2017. Pengambilan sampel menggunakan consecutive sampling dengan jumlah 52 responden yang terbagi menjadi kelompok intervensi dan kelompok kontrol.

Pengumpulan data dilakukan dengan 4 sesi, yaitu: Sesi 1: Mengidentifikasi kemampuan keluarga dan sistem pendukung yang ada; Sesi 2: Menggunakan sistem pendukung dalam keluarga, memonitor dan hambatannya; sesi 3: menggunakan sistem pendukung di luar keluarga, memonitor dan hambatannya; sesi 4: mengevaluasi hasil 
dari hambatan penggunaan sistem pendukung.

Instrumen yang digunakan adalah kuesioner kemampuan kognitif, kemampuan afektif dan kemampuan psikomotor yang telah dikembangkan oleh Wahyuningsih (2011) dan telah diuji validitas dengan nilai Cronbach's Alpha masing-masing 0,883, 0,328 dan 0,502. Pengujian statistik penelitian ini menggunakan analisis Man Whitney dengan kemaknaan hasil uji ditentukan berdasarkan nilai $\mathrm{p}<0,05$.

\section{HASIL}

\section{Analisis Univariat}

\section{a. Karakteristik Keluarga}

Dari tabel 1 dapat dilihat pada variabel usia didapatkan hampir sama antara kelompok intervensi dan kelompok kontrol. Hasil tersebut menunjukkan bahwa rerata usia keluarga pada kelompok intervensi dan kelompok kontrol pada usia dewasa tengah. Tabel 1 juga menunjukkan bahwa lama merawat klien GGK didapatkan rerata 29,81 pada kelompok intervensi dan 23,72 pada kelompok kontrol, sehingga dapat dikatakan bahwa lama merawat pada kedua kelompok berbeda, tetapi pada nilai tengah sama (24 bulan).

Tabel 2 menunjukkan bahwa jenis kelamin, pekerjaan dan pendidikan pada kelompk intervensi dan kelompok kontrol memiliki proporsi yang hampir sama dimana sebagian besar responden berjenis kelamin perempuan, tidak bekerja dan berpendidikan SMU.

Tabel 1.

Distribusi rerata usia keluarga klien GGK pada kelompok intervensi dan kelompok kontrol $(\mathrm{n} 1=27, \mathrm{n} 2=25)$

\begin{tabular}{lllcccc}
\hline \multicolumn{1}{c}{ Variabel } & Kelompok & Mean & Median & SD & Min-Maks & 95\% CI \\
\hline \multirow{2}{*}{ Usia } & Intervensi & 44,04 & 43 & 10,97 & $25-70$ & $39,7-48,4$ \\
\cline { 2 - 7 } & Kontrol & 40,36 & 38 & 12,38 & $23-73$ & $35,3-45,4$ \\
\hline \multirow{2}{*}{$\begin{array}{l}\text { Lama } \\
\text { Rawat }\end{array}$} & Intervensi & 29,81 & 24 & 14,61 & $6-54$ & $20,0-31,6$ \\
\cline { 2 - 7 } & Kontrol & 23,72 & 24 & 14,83 & $6-54$ & $17,6-29,87$ \\
\hline
\end{tabular}

Tabel 2.

Distribusi Frekuensi Berdasarkam Jenis Kelamin, Pekerjaan, Dan Pendidikan Keluarga Klien GGK Pada Kelompok Intervensi Dan Kelompok Kontrol $(\mathrm{n} 1=27, \mathrm{n} 2=25)$

\begin{tabular}{|c|c|c|c|c|c|c|}
\hline \multirow[t]{2}{*}{ Karakteristik } & \multicolumn{2}{|c|}{$\begin{array}{l}\text { Kelompok } \\
\text { Intervensi }\end{array}$} & \multicolumn{2}{|c|}{$\begin{array}{c}\text { Kelompok } \\
\text { Kontrol }\end{array}$} & \multicolumn{2}{|c|}{ Total } \\
\hline & $\mathbf{n}$ & $\%$ & $\mathbf{n}$ & $\%$ & $\mathbf{n}$ & $\%$ \\
\hline \multicolumn{7}{|l|}{ Jenis Kelamin } \\
\hline a. Laki-laki & 8 & 29,6 & 10 & 40 & 18 & 34,6 \\
\hline b. Perempuan & 19 & 70,4 & 15 & 60 & 34 & 65,4 \\
\hline \multicolumn{7}{|l|}{ Pekerjaan } \\
\hline a. Bekerja & 10 & 37 & 11 & 44 & 21 & 40,4 \\
\hline b. Tidak Bekerja & 17 & 63 & 14 & 56 & 31 & 59,6 \\
\hline \multicolumn{7}{|l|}{ Pendidikan } \\
\hline a. SD & 6 & 22,2 & 4 & 16 & 10 & 19,2 \\
\hline b. SMP & 7 & 25,9 & 3 & 12 & 10 & 19,2 \\
\hline c. SMU & 9 & 33,3 & 13 & 52 & 22 & 42,3 \\
\hline d. Sarjana & 5 & 18,5 & 5 & 20 & 10 & 19,2 \\
\hline
\end{tabular}




\section{b. Kemampuan Keluarga}

Tabel 3 dibawah menunjukkan bahwa nilai rerata kemampuan keluarga berdasarkan kemampuan kognitif, psikomotor pada kelompok intervensi dan kemampuan afektif dan kemampuan kelompok kontrol sebelum diberikan perlakuan supportive therapy hampir sama.

Tabel 3.

Distribusi Frekuensi Kemampuan Kognitif, Kemampuan Afektif dan Kemampuan Psikomotor Keluarga Klien GGK Pada Kelompok Intervensi Dan Kelompok Kontrol (n1 = 27, n2 = 25)

\begin{tabular}{lcccccccc}
\hline \multirow{2}{*}{ Variabel } & \multicolumn{4}{c}{ Kelompok Intervensi } & \multicolumn{4}{c}{ Kelompok Kontrol } \\
\cline { 2 - 9 } & Mean & Median & SD & Min-max & Mean & Median & SD & Min-max \\
\hline $\begin{array}{l}\text { Kemampuan } \\
\text { Kognitif }\end{array}$ & 49,15 & 48 & 6,57 & $40-60$ & 47,76 & 48 & 6,13 & $40-60$ \\
\hline $\begin{array}{l}\text { Kemampuan } \\
\text { Afektif }\end{array}$ & 12,56 & 12 & 2,15 & $10-16$ & 12,48 & 12 & 2,18 & $8-16$ \\
\hline $\begin{array}{l}\text { Kemampuan } \\
\text { Psikomotor }\end{array}$ & 23,11 & 23 & 2,98 & $20-28$ & 25,44 & 25 & 3,15 & $22-32$ \\
\hline
\end{tabular}

\section{Analisa Bivariat}

a. Kemampuan Keluarga Klien GGK Sebelum dan Sesudah Diberikan Supportive Therapy pada Kelompok Intervensi

Tabel 4 menunjukkan bahwa terdapat selisih rata-rata kemampuan keluarga pada kelompok intervensi berdasarkan kemampuan kognitif sebelum dan sesudah sebesar 7,81, kemampuan afektif sebelum dan sesudah sebesar 5,85, dan kemampuan psikomotor sebelum dan sesudah sebesar 6,96. Hasil uji Wilcoxon Sign Rank Test didapat $\mathrm{p}$ value pada ketiga kemampuan keluarga sebesar 0,001 artinya ada perbedaan antara kemampuan keluarga sebelum dan sesudah pemberian supportive therapy.

Tabel 4.

Analisis Kemampuan Kognitif, Kemampuan Afektif dan Kemampuan Psikomotor Keluarga Klien GGK Sebelum dan Sesudah Intervensi Pada Kelompok Intervensi (n1 = 27)

\begin{tabular}{lccccc}
\hline \multicolumn{1}{c}{ Variabel } & Mean & Median & SD & 95\% CI & P Value \\
\hline Kemampuan Kognitif & & & & & \\
a. Sebelum & 49,15 & 48 & 6,57 & $46,6-51,8$ & 0,001 \\
b. Sesudah & 56,96 & 56 & 3,30 & $55,7-58,3$ & \\
Selisih & 7,81 & & & & \\
\hline Kemampuan Afektif & & & & & \\
a. Sebelum & 12,56 & 12 & 2,15 & $11,7-13,4$ & 0,001 \\
b. Sesudah & 18,41 & 19 & 1,67 & $17,8-19,1$ & \\
Selisih & 5,85 & & & & \\
\hline Kemampuan Psikomotor & & & & & \\
a. Sebelum & 23,11 & 23 & 2,98 & $21,9-24,3$ & \\
b. Sesudah & 30,07 & 30 & 1,86 & $29,3-30,8$ & \\
Selisih & 6,96 & & & & \\
\hline
\end{tabular}

\section{b. Kemampuan Keluarga Sebelum dan Sesudah pada Kelompok Kontrol}

Tabel 5 menunjukkan bahwa terdapat selisih rata-rata kemampuan keluarga pada kelompok kontrol berdasarkan kemampuan kognitif sebelum dan sesudah sebesar 3,28, kemampuan afektif sebelum dan sesudah sebesar 4,56, dan kemampuan psikomotor 
sebelum dan sesudah sebesar 1,32. Hasil uji Wilcoxon Sign Rank Test didapat $\mathrm{p}$ value pada ketiga kemampuan keluarga <
0,05 artinya ada perbedaan antara kemampuan keluarga sebelum dan sesudah.

Tabel 5.

Analisis Kemampuan Kognitif, Kemampuan Afektif dan Kemampuan Psikomotor Keluarga Klien GGK Sebelum dan Sesudah Intervensi Pada Kelompok Kontrol (n2=25)

\begin{tabular}{lccccc}
\hline \multicolumn{1}{c}{ Variabel } & Mean & Median & SD & 95\% CI & P Value \\
\hline Kemampuan Kognitif & & & & & \\
a. Sebelum & 47,76 & 48 & 6,13 & $45,2-50,3$ & 0,001 \\
b. Sesudah & 51,04 & 50 & 4,25 & $49,3-52,8$ & \\
Selisih & 3,28 & & & & \\
\hline Kemampuan Afektif & & & & & \\
a. Sebelum & 12,48 & 12 & 2,18 & $11,6-13,4$ & 0,001 \\
b. Sesudah & 14,04 & 15 & 1,90 & $13,3-14,8$ & \\
Selisih & 4,56 & & & & \\
\hline Kemampuan Psikomotor & & & & & \\
a. Sebelum & 25,44 & 25 & 3,15 & $24,1-26,7$ & 0,014 \\
b. Sesudah & 26,76 & 28 & 2,89 & $25,6-27,9$ & \\
Selisih & 1,32 & & & & \\
\hline
\end{tabular}

c. Kemampuan Keluarga sesudah diberikan Supportive Therapy Pada Kelompok Intervensi dan Kelompok Kontrol

Tabel 6 didapatkan bahwa kemampuan kognitif, kemampuan afektif dan kemampuan psikomotor antara kelompok intervensi dan kelompok kontrol sesudah pemberian supportive therapy terjadi peningkatan yang bermakna. Hasil uji Mann Whitney didapatkan $\mathrm{p}<0,05$ artinya ada perbedaan antara kemampuan kognitif, kemampuan afektif, kemampuan psikomotor sesudah pemberian pada kedua kelompok.

Tabel 6

Analisis Kemampuan Kognitif, Kemampuan Afektif dan Kemampuan Psikomotor Keluarga Klien GGK Sesudah Intervensi Pada Kelompok Intervensi dan Kelompok Kontrol (n1 = 27, n2 = 25)

\begin{tabular}{ccccc}
\hline Variabel & Kelompok & Mean & SD & \multirow{2}{*}{ P Value } \\
\hline \multirow{2}{*}{ Kemampuan Kognitif } & Intervensi & 56,96 & 3,30 & \multirow{2}{*}{0,001} \\
\cline { 2 - 4 } & Kontrol & 51,04 & 4,25 & \\
\hline \multirow{2}{*}{ Kemampuan Afektif } & Intervensi & 18,41 & 1,67 & \\
\cline { 2 - 4 } & Kontrol & 14,24 & 1,90 & 0,001 \\
\hline \multirow{2}{*}{ Kemampuan Psikomotor } & Intervensi & 30,07 & 1,86 & \\
\cline { 2 - 4 } & Kontrol & 26,76 & 2,89 & 0,001 \\
\hline
\end{tabular}

\section{PEMBAHASAN}

Berdasarkan hasil penelitian didapatkan bahwa kemampuan keluarga sebelum diberikan supportive therapy pada kemampuan kognitif sebesar 49,15, kemampuan afektif sebesar 12,56 dan kemampuan psikomotor sebesar 23,11.
Sedangkan, kemampuan keluarga pada kelompok kontrol berdasarkan kemampuan kognitif sebesar 47,76, kemampuan afektif 12,48 dan 25,44 pada kemampuan psikomotor. Hasil analisis menunjukkan bahwa pada kelompok yang mendapatkan supportive therapy memperlihatkan adanya peningkatan kemampuan keluarga dalam 
merawat klien GGK berdasarkan kemampuan kognitif, kemampuan afektif dan kemampuan psikomotor sebesar 5,857,81 dengan hasil uji statistik $\mathrm{p}$ value < 0,05 sehingga ini berarti ada perbedaan yang signifikan terhadap kemampuan keluarga dalam merawat klien GGK setelah diberikan intervensi supportive therapy. Hasil penelitian ini sesuai dengan penelitian yang dilakukan oleh Damayanti (2014), Hernawaty (2009), Nyumirah (2013) dan Widiastuti (2010) yang menyatakan bahwa kemampuan kognitif, kemampuan afektif dan kemampuan psikomotor pada pasien dapat meningkat dengan rata-rata peningkatan antara 3,5713.00 setelah diberikan supportive therapy.

Terapi supportif suatu bentuk terapi alternative yang mempunyai tujuan untuk menolong pasien beradaptasi dengan baik terhadap suatu masalah yang dihadapi dan utnuk mendapatkan suatu kenyamanan hidup terhadap gangguan kea rah keseimbangan, yang terutama dilakukan adalah menekan atau mengontrol gejala - gejala yang terjadi dan untuk menstabilkan pasien ke alam suasana yang aman dan terlinduni untuk melawan ataupun menghadapi tekanan yang mungkin saja berat, baik yang datang dari luar maupun dari dalam dirinya.

Kemampuan keluarga merawat pasien yang menjalani terapi hemodialisa dapat mempengaruhi status kesehatan pasien dimana semakin baik keluarga merawat pasien maka akan semakin meningkat derajat kesehatan dan kualitas hidup pasien. Hal ini sejalan dengan penelitian yang dilakukan Damayanti (2014) yang menyatakan bahwa kemampuan keluarga yang baik dalam merawat anggota keluarga yang sakit dapat mempercepat kesembuhan pasien baik secara fisik maupun mental. Friedman (2017) mengemukakan bahwa kemampuan keluarga dalam memberikan asuhan kesehatan mempengaruhi status kesehatan keluarga dimana keluarga berperan dalam mengenal masalah kesehatan dan mengidentifikasi masalah dalam keluarga.

Menurut Perry \& Potter (2011), Kemampuan keluarga merawat anggota keluarga yang sakit terdiri dari 3 komponen yaitu: kemampuan kognitif, kemampuan afektif dan kemampuan psikomotor.

Friedman, (2010), menyatakan bahwa kemampuan keluarga dalam memberikan asuhan kesehatan dan mempengaruhi status kesehatan keluarga antara lain dengan mengenal masalah kesehatan dan keluarga mampu mengidentifikasi masalah-masalah dalam keluarga. Kemampuan keluarga dalam membuat keputusan dan merencanakan tindakan keperawatan merupakan salah satu fungsi keluarga dimana hal ini dapat diartikan bahwa keluarga mampu merawat anggota keluarga sebelum membawanya ke pelayanan kesehatan.

Keluarga yang diberikan informasi kesehatan akan membentuk tindakan keluarga yang merujuk pada pikiran rasional, mempelajari fakta, mengambil keputusan dan mengembangkan pikiran (Craven, 2006). Notoadmodjo (2010), menyatakan bahwa pengetahuan seseorang tidak hanya didapat dari pendidikan formal (sekolah dan universitas), namun dapat juga terbentuk dari pengalaman dan pendidikan non formal seperti membaca dan mendapatkan penyuluhan. Pendidikan non formal yang diterima oleh seseorang menimbulkan adanya pengalamanpengalaman baru dalam meningkatkan kemampuan seseorang membantu klien GGK. Caregiver dengan klien GGK diperlukan pengetahuan yang tinggi untuk 
memberikan pemahaman dan keyakinan tentang perawatan dan meningkatkan motivasi klien agar klien dapat menjalankan hemodialisa secara rutin dan menyadari fungsi dan manfaat hemodialisa untuk diri sendiri. Supportive therapy yang diberikan menjelaskan bahwa terapi ini merupakan sumber informal bagi keluarga yang dapat meningkatkan kemampuannya merawat anggota keluarga lainnya.

Menurut Townsend (2009), supportive therapy merupakan suatu bentuk terapi yang terprogram waktu dengan baik (Time Limited Program). Maksudnya adalah proses pelaksanaan terapi dapat berjalan beberapa minggu sampai bulan. Pada pelaksanaannya teori ini sangat mendukung pelaksanaan supportive therapy yang dilaksanakan peneliti pada keluarga yang merawat klien GGK yang menunjukkan adanya kesamaan sesuai dengan diawal perencanaan terapi ini akan dilakukan dalam 1 kali pertemuan dalam setiap sesi.

\section{KESIMPULAN}

Berdasarkan hasil analisis dan
pembahasan diatas maka dapat disimpulkan bahwa Penerapan Supportive Therapy dapat dilanjutkan di ruang hemodialisa dan penerapan mandiri oleh keluarga klien di rumah. Kegiatan monitoring secara berkala setelah pelaksanaan penelitian ini perlu dilakukan dengan tujuan untuk mengevaluasi kemampuan keluarga dalam merawat klien GGK yang menjalani hemodialisa rutin.

\section{DAFTAR PUSTAKA}

Arikunto, S. (2013). Prosedur penelitian: suatu pendekatan praktik. Jakarta: Rineka Cipta
Chien, W.T., Chan,S.W.C,dan Thompson, D.R. (2006). Effects of a mutual support groups for families of chinese people with schizophrenia:18-months followup. Diakses 18 Februari 2017. Website: http//www.proquest.com.pqdauto.

Craven,R.F.\& Himle,C.J. (2006). Fundamental of nursing, human health and function.(5th,ed). Lippincott; Williams \& Wilkins

Damayanti, R., Hernawaty, T. (2014). Pengaruh Terapi Supportif Keluarga Terhadap Kemampuan Keluarga Merawat Klien Ganggua Jiwa di Kecamatan Bogor Timur. Konseli: Jurnal Bimbingan da Konseling. 1 (1). doi.org/10.24042/kons.v1i1.310

Friedman, M. (2017). Buku Ajar Keperawatan Keluarga: Riset Teori Dan Praktik. Edisi 5. Jakarta : EGC.

Guyton, A.C., \& Hall, J.E. (2016). Buku Ajar Fisiologi Kedokteran. Jakarta : EGC.

Hamid,A.Y. (2008). Buku ajar riset penelitian;konsep, etika,\& instrumentasi. Edisi 2. Jakarta.EGC

aryanti \& Nisa, K. (2015). Terapi Konservatif dan Terapi Pengganti Ginjal Sebagai Penatalaksanaan Pada Gagal Ginjal Kronik. Februari 19, 2017. http://jukeunila.com

Hastono, S.P.(2007). Modul analisis data kesehatan. Jakarta :FKM-UI (tidak dipublikasikan).

Hernawaty, T. (2010). Pengaruh terapi suportif terhadap kemampuan keluarga dalam merawat klien gangguan jiwa di Bubulak Bogor. Tidak dipublikasikan 
Keliat.(2003). Disertasi. pemberdayaan klien dan keluarga dalam keperawatan klien skizofrenia dengan perilaku kekerasan di Rumah Sakit Jiwa Pusat Bogor. Jakarta.(tidak dipublikasikan).

Kristianingsih. T. (2009). Pengaruh Cognitive Therapy pada Klien GGK yang menjalani Hemodialisa di Rumah Sakit Fatmawati. Tidak dipublikasikan

Murthy,S.(2003). Family interventions and empowerment as an approach to enhance mental health resources in developing countries. Diakses 18 Februari $2017 . \quad$ Website: http://www.pubmedcentral.nih.gov.

Muttaqin, A., \& Sari, K. (2011). Asuhan Keperawatan Sistem Perkemihan. Jakarta : Salemba Medika.

Notoatmodjo, S. (2010). Metodologi Penelitian Kesehatan. Edisi Revisi. Jakarta: Rineka Cipta.

Nyumirah, S. (2013). Peningkatan Kemampuan Interaksi Sosial (Kognitif, Afektif Dan Perilaku) Melalui Penerapan Terapi Perilaku Kognitif Di Rsj Dr Amino Gondohutomo Semarang. Jurnal Keperawatan Jiwa. 1 (2). 121-128

Padila. (2012). Buku Ajar Keperawatan Keluarga. Jogjakarta : Nuha Medika.

Potter \& Perry. (2011). Fundamental Of Nursing: Fundamental Keperawatan, (Edisi 7). Jakarta : Salemba Medika.

Prabowo, E., \& Pranata, A. (2014). Buku Ajar Asuhan Keperawatan Sistem Perkemihan. Yogyakarta : Nuha Medika.
Price, S.A.(2012). Patofisiologi: Konsep klinis proses-proses penyakit. Jakarta: EGC

Smeltzer, S.S.B.(2014). Buku ajar keperawatan medical bedah, Jakarta: EGC

Sugiyono.(2007). Statistika untuk penelitian. Bandung: Alfabeta

Suharjono.(2008).Ilmu penyakit dalam.Jakarta; Penerbit FKUI

Townsend, C.M.(2009). Psychiatric of nursing .(3th, ed).Philadelphia:F.A.Davis Company

Widiastuti, S.H.(2010). Pengaruh terapi kelompok suportif terhadap kemampuan keluarga dalam melatih "self care" anak tunanetra ganda di SLB G di Jakarta. Tidak dipublikasikan 